Lorena Oliveira Dantas Maynard ${ }^{1}$ Isabel Maria Sampaio Oliveira Lima ${ }^{1}$ Yara Oyram Ramos Lima ${ }^{2}$ Ediná Alves Costa ${ }^{2}$

\title{
OS CONFLITOS DO CONSENTIMENTO ACERCA DA DOAÇÃO DE ÓRGÃOS POST MORTEM NO BRASIL
}

Conflict of consent for post mortem organs donation in Brazil

${ }^{1}$ Universidade Católica do Salvador. Salvador/BA, Brasil.

2 Universidade Federal da Bahia. Salvador/BA, Brasil.

Correspondência: Lorena Oliveira Dantas Maynard. E-mail: maynardlorena@gmail.com.

Recebido em: 06/04/2015. Revisado em: 06/08/2015. Aprovado em: 13/08/2015. 


\section{RESUMO}

Com o refinamento das técnicas de cirurgias e imunogenética pela medicina nas últimas décadas e com os avanços na farmacoterapia, o transplante de órgãos e tecidos tornou-se uma possibilidade real e uma alternativa essencial ao prolongamento e à qualidade da vida humana. Este estudo objetivou analisar o consentimento para remoção de órgãos e tecidos post mortem na legislação brasileira, na perspectiva da autorização da família. Adotou-se, para tanto, estratégia metodológica qualitativa através de revisão de literatura e revisão legislativa, que permitem um aprofundamento no universo dos significados, dos motivos, das aspirações, das crenças, dos valores e das atitudes em relação ao tema. Os resultados apontam que, na atual Lei de Transplantes, os direitos da personalidade e o princípio da autonomia da vontade são institutos pouco homenageados em função da predominância do monopólio da decisão familiar na hipótese de um confronto entre a vontade do doador e a vontade da família. Frente ao problema da escassez de órgãos no país, a solução mais consentânea com a justiça seria uma adequação entre os dispositivos de lei do Código Civil e da Lei de Transplantes. Oportuno partir do texto já existente do artigo $4^{\circ}$ da Lei n. 9.434/1997, para incluir a manifestação da vontade do doador em vida, devidamente documentada. É igualmente importante a informação e a conscientização popular sobre a natureza humanitária da doação de órgãos como medidas direcionadas à discussão do princípio da solidariedade para uma política de doação de órgãos.

\section{Palavras-Chave}

Autonomia da Vontade; Consentimento; Doação de órgãos; Família; Transplantes.

\section{ABSTRACT}

Given the refinement in surgical, immunogenetic and pharmacotherapeutic techniques fostered by medicine in the last few decades, organ and tissue transplantation has become a real possibility and an essential alternative towards the extension and quality of human life. This study aimed to analyze the consent for post mortem organ and tissue removal in Brazilian law, from the perspective of the authorization of the family. A qualitative methodological approach was adopted, using literature and legislative reviews, and allowing a deeper insight into the meanings, motives, aspirations, beliefs, values and attitudes surrounding the subject. Results showed that, in the current Transplant Act, and in the event of a confrontation between the will of the donor and the family's wishes, personality rights and the principle of freedom of choice are underestimated at the expense of the prevailing monopoly of the family decision-making process. In view of the organ shortages faced by the country, the solution that is most consentaneous to justice would be to tailor the dispositions of the Transplant Act to those of the Civil Code. It would be suitable to take the existing wording in Article 4 of Law 9,434/97 and to include the duly documented expression of the donor's will before death. Public awareness and information about the humanitarian nature of organ donation are likewise important as measures aimed at discussing the principle of solidarity for an organ donation policy.

\section{Keywords}

Consent; Family; Freedom of Choice; Organ Donation; Transplants. 


\section{Introdução}

Os temas doação e transplante de órgãos relacionam formas possíveis de continuidade da vida, mediante gesto de solidariedade, seja do doador ou de sua família. Embora relevante - pela natureza e pelo valor intangível da iniciativa do doador ou do desprendimento da família enlutada -, no Brasil, o assunto passou a ser objeto de interesse do direito há menos de seis décadas ${ }^{1}$.

Enquanto temas atuais, dado o avanço da medicina na busca de soluções para o prolongamento da vida humana e a redução do sofrimento, a doação e o transplante de órgãos têm enfrentado contínuos desafios. As relações sociais, a complexidade do cotidiano, os significativos avanços tecnológicos e científicos na área de saúde, o refinamento das técnicas cirúrgicas, da imunogenética e da farmacoterapêutica têm levado o direito a interagir com um novo conjunto de questões relacionadas ao direito à saúde e à vida.

Apesar de o transplante de órgãos constituir uma técnica valiosa, a demanda de receptores ainda é muito superior à disponibilidade de doadores, circunstância que impede que os bancos de órgãos atendam a todos os que deles necessitam, ensejando longas filas de espera por órgãos no Brasil.

Mesmo com a tendência crescente de transplantes, a realidade ainda é desfavorável para os que necessitam dessa medida extrema para sobreviver, devido à necessidade de doadores no Brasil. Segundo dados divulgados pela Associação Brasileira de Transplante de Órgãos (ABTO) ${ }^{2}$, no primeiro semestre de 2014 houve significativo aumento no número de doadores efetivos no país, com 12,8 doadores por milhão de pessoas (pmp), considerando-se a média de 2010 (9,9 pmp). Contudo, em comparação com países como Espanha e Canadá, que mantêm médias acima de 20 doadores pmp, o Brasil ainda tem um longo caminho a percorrer³ .

Ao identificar a natureza do interesse e o direito humano envolvido, o Estado passou a agir e a estabelecer as diretrizes e os critérios de acesso e uso médico da técnica de transplante de órgãos, tecidos e partes do corpo humano. Nessas bases, identifica-se a necessidade de uma legislação capaz não apenas de garantir a integridade física e a dignidade da pessoa humana. Reconhece-se a relevância de lei que facilite a captação e distribuição de órgãos para mitigar os principais empecilhos no processo da doação e do transplante de órgãos. Entre

${ }^{1}$ ROZA, Bartira de Aguiar; ODIERNA, Maria Teresa Aparecida da Silva; GLEZER, Milton; SÁ, João Roberto de. Captação de órgãos para transplantes, 2006. Disponivel em: <http://www.abto.org.br/abtov03/Upload/ file/Biblioteca_Teses/Textos/CaptacaodeOrgaosLivroEliasKnobellBartira.pdf>. Acesso em 26 nov. 2014.

${ }^{2}$ ABTO. Relatório Brasileiro de Transplantes, ano 20, n. 1, 2014. Disponível em: <http://www.abto.org.br/ abtov03/Upload/file/RBT/2014/rbt2014parc-jan-mar.pdf> Acesso em: 10 nov. 2014.

${ }^{3}$ BRASIL bate recorde em doação de órgãos. Ministério da Saúde, 2011. Disponível em:<http://portal. saude.gov.br/portal/aplicacoes/noticias/default.cfm?pg=dspDetalheNoticia\&id_area=124\&CO_NOTI$\mathrm{ClA}=12289>$ Acesso em: 23 mai. 2012. 
esses empecilhos, Rech e Rodrigues Filho ${ }^{4}$ registram a falta de identificação do paciente em morte encefálica (ME), o manuseio inadequado do doador e a recusa familiar para doação de órgãos.

Em face da problemática, este estudo tem o objetivo de analisar a autorização para remoção de órgãos e tecidos post mortem na legislação brasileira, na perspectiva do consentimento da família. Do exame da Lei n. 9.434/19975 (Lei de Transplantes) depreende-se que a manifestação de vontade expressa e pública do potencial doador quanto à doação de seus órgãos não está juridicamente protegida. Em contrapartida, a decisão sobre a (não) doação de órgãos é inteiramente da família do doador, mesmo que esta decisão contrarie sua vontade. Dadas a importância social e as consequências jurídicas da expressão da vontade do doador capaz, o tema justifica um estudo.

No Brasil, o ordenamento jurídico sobre doação tem por característica o consentimento explícito, que apresenta taxas de doação de $25 \%$ a $30 \%$ mais baixas do que nos países onde o consentimento é presumido. Entretanto, considera-se que, para além do consentimento presumido, outros fatores influenciam o aumento das doações, como a estrutura dos serviços de saúde, os gastos com a saúde e o consentimento familiar ${ }^{6}$.

Em face da centralidade da decisão familiar quanto à possível doação de órgãos de um de seus membros, tem-se que os direitos da personalidade e o princípio da autonomia da vontade são institutos preteridos na hipótese de um confronto entre a vontade do doador e a vontade da família. A falta da previsão legal para esse confronto gera dificuldades em encontrar uma solução coerente que respeite os institutos citados e possibilita, ainda, uma decisão que pode não ser a melhor para a sociedade. Uma análise da atual Lei de Transplantes permite aprofundar a discussão da tutela do direito fundamental à vida e à saúde e ao direito personalíssimo de autonomia da vontade do ser humano.

A revisão da legislação constituiu um dos eixos do estudo, na medida em que o tema foi contextualizado cronológica e historicamente, permitindo observar

\footnotetext{
${ }^{4}$ RECH, Tatiana H.; RODRIGUES, Édson Moraes. Entrevista familiar e consentimento. Rev. bras. ter. Intensiva, São Paulo, v. 19, n. 1 mar. 2007. Disponivel em <http://www.scielo.br/scielo.php?script=sci_ arttext\&pid=S0103-507X2007000100011\&Ing=pt\&nrm=iso>. Acesso em: 21 mai. 2012. http://dx.doi.org/10.1590/S0103-507X2007000100011.

${ }^{5}$ BRASIL. Lei Federal n. 9.434, de 04 de fevereiro de 1997. Dispõe sobre a remoção de órgãos, tecidos e partes do corpo humano para fins de transplante e tratamento e dá outras providências. Disponível em: <http://www.planalto.gov.br/ccivil_03/LEIS/L9434compilado.htm>. Acesso em: 29 jan. 2016.

${ }^{6}$ ZÚÑIGA-FAJURIA, Alejandra Increasing organ donation by presumed consent and allocation priority: Chile. Bull World Health Organ., v. 93, p. 199-202, 2015; ABADIE, Alberto; GAY, Sebastien. The impact of presumed consent legislation on cadaveric organ donation: a cross country study. J Healthy Econ. v. 25, n. 4, p. 599-620, Dec. 2005. Disponível em: <http://www.ksg.harvard.edu/fs/aabadie/pconsentp.pdf>. Acesso em 26 nov. 2014. 10.1016/j.jhealeco.2006.01.003.
} 
a evolução do tratamento dado pelo legislador à matéria a partir da análise dos principais textos normativos.

\section{A doação de órgãos na legislação brasileira}

O tema da doação de órgãos no Brasil só constituiu objeto de legislação própria em 1963, com a edição da Lei n. 4.280/19637. A insuficiência de avanços médicos sobre transplante de órgãos à época pode ter sido o fato gerador para que a regulamentação sobre o tema seja relativamente recente.

A Lei n. 4.280/1963 tinha como ementa o seguinte texto: "Dispõe sobre a extirpação de órgãos ou tecidos de pessoa falecida" (destaque das autoras). O uso da expressão "extirpação" foi duramente criticado à época por imprimir a ideia de que os órgãos seriam retirados com violência. Andrade $e^{8}$ adverte também para uma impropriedade da expressão "pessoa falecida”, dado que, para o Direito Civil, a condição de pessoa termina com a morte, desconstituindo, portanto, sua qualidade intrínseca.

A lei dispunha somente acerca da extirpação de órgãos de cadáveres, possibilidade que se apresentava como a única circunstância possível em face da inexistência da regulamentação do transplante entre vivos. Sobre o consentimento para doação, a lei permitia, em seu artigo $1^{\circ}$, a retirada de órgãos somente mediante autorização expressa e por escrito do doador, desde que feita em vida, ou, na falta desta, quando não houvesse oposição do cônjuge, dos parentes até segundo grau ou de corporações civis ou religiosas que fossem responsáveis pelo destino dos despojos. Nesse contexto, observa-se que se entendeu priorizada a vontade do potencial doador sobre a da instituição familiar.

Não havia objeção explícita na lei quanto à doação com caráter não gratuito, omissão que teria dado margem a interpretações de que estaria autorizada a comercialização de órgãos.

Por fim, o referido diploma não estabeleceu critérios técnicos para constatação da morte do doador, exigindo tão somente que a morte estivesse "provada de maneira cabal". A expressão foi considerada imprópria, uma vez que abriu margem para diversas possibilidades interpretativas e, consequentemente, para a insegurança jurídica diante dessa imprecisão terminológica.

\footnotetext{
${ }^{7}$ BRASIL. CÂMARA DOS DEPUTADOS. Lei n. 4.280, de 06 de novembro de 1963. Dispõe sobre a extirpação de órgão ou tecido de pessoa falecida. Disponível em: <http://www2.camara.leg.br/legin/fed/lei/1960-1969/ lei-4280-6-novembro-1963-353353-norma-pl.html>. Acesso em: 29 jan. 2016.

${ }^{8}$ ANDRADE, Taciana Palmeira. Doação de órgãos post mortem: a viabilidade de adoção pelo sistema brasileiro da escolha pelo doador do destinatário dos seus órgãos. 2009. Programa de Pós-Graduação em Direito - Faculdade de Direito. Universidade Federal da Bahia, Salvador, 2009. Disponível em <https://repositorio.ufba.br/ri/bitstream/ri/12492/1/TACIANA\%20PALMEIRA\%20ANDRADE.pdf>. Acesso em: 20 nov. 2014.
} 
A revogação da Lei n. 4.280/1963 se deu com a edição da Lei 5.479/19689, cujo texto corrigiu alguns dos equívocos da lei anterior. A palavra "extirpação" foi substituída pela palavra "retirada", assim como a palavra "cadáver" substituiu a expressão "pessoa falecida". Ademais, permitiu-se expressamente a doação entre vivos com o texto do artigo $10^{10}$.

Ao contrário da lei anterior, esta proibia implicitamente a disposição onerosa do corpo, como se depreende da leitura do artigo 10: "A disposição gratuita de uma ou várias partes do corpo post mortem, para fins terapêuticos, é permitida na forma desta lei”. Tal alteração veio a representar, afinal, uma mudança substancial a respeito da temática.

A Lei n. 5.479/1968 exigia, tal como a legislação anterior, o consentimento expresso do doador e a subsidiariedade da manifestação familiar em casos de omissão daquele doador quando ainda em vida. O diploma inovou ao restringir a opção pelo transplante somente quando esgotados todos os outros meios de tratamento, como uma medida de exceção.

Com a promulgação da Constituição Federal de 1988 (CF/88), a doação e o transplante de órgãos, tecidos e partes do corpo humano foram elevados a uma matéria constitucional, conforme o artigo 199, parágrafo $4^{\mathrm{o} 11}$.

A Carta Magna reverenciou a legislação de 1968, ao vedar explicitamente a comercialização de órgãos. $\mathrm{O}$ artigo em questão trata de norma programática que deu origem à Lei n. 8.489/1992 ${ }^{12}$, regulamentada pelo Decreto n. 879/1993 ${ }^{13}$. Este decreto revogou expressamente a Lei n. 5.479/1968. Em consonância com o preceito constitucional e com a lei de transplantes que a antecedeu, a Lei n. 8.489/1992 estabeleceu a gratuidade da doação de órgãos e manteve, tal como

\footnotetext{
${ }^{9}$ BRASIL. CÂMARA DOS DEPUTADOS. Lei n. 5.479, de 10 de agosto de 1968. Dispõe sobre a retirada e transplante de tecidos, órgãos e partes de cadáver para finalidade terapêutica e científica, e dá outras providências. Disponível em: <http://www2.camara.leg.br/legin/fed/lei/1960-1969/lei-5479-10-agosto1968-358591-norma-pl.html>. Acesso em: 29 jan. 2016.

${ }^{10}$ Artigo 10: “É permitido à pessoa maior e capaz dispor de órgãos e partes do próprio corpo vivo, para fins humanitários e terapêuticos". Id. Ibid.

11 “Art. 199. A assistência à saúde é livre à iniciativa privada. [...]§ $4^{\circ} \mathrm{A}$ lei disporá sobre as condições e os requisitos que facilitem a remoção de órgãos, tecidos e substâncias humanas para fins de transplante, pesquisa e tratamento, bem como a coleta, processamento e transfusão de sangue e seus derivados, sendo vedado todo tipo de comercialização". (destaques das autoras) BRASIL. Constituição da República Federativa do Brasil de 1988. Disponível em: < http://www.planalto.gov.br/ccivil_03/constituicao/ConstituicaoCompilado.htm>. Acesso em: 29 jan. 2016.

${ }^{12}$ BRASIL. CÂMARA DOS DEPUTADOS. Lei n. 8.489, de 18 de novembro de 1992. Dispõe sobre a retirada e transplante de tecidos, órgãos e partes do corpo humano, com fins terapêuticos e científicos e dá outras providências. Disponível em: <http://www2.camara.leg.br/legin/fed/lei/1992/lei-8489-18-novembro1992-363720-norma-pl.html>. Acesso em: 29 jan. 2016.

${ }^{13}$ BRASIL. Decreto n. 879, de 22 de julho de 1993. Regulamenta a Lei n. 8.489, de 18 de novembro de 1992, que dispõe sobre a retirada e o transplante de tecidos, órgãos e partes do corpo humano, com fins terapêuticos, científicos e humanitários. Disponível em: <http://www.planalto.gov.br/ccivil_03/decreto/1990-1994/D0879.htm>. Acesso em: 29 jan. 2016.
} 
elucida Andrade ${ }^{14}$, a imposição de que o transplante somente fosse realizado desde que não causasse nenhum prejuízo para o disponente e desde que fosse indispensável para o paciente receptor.

Tendo a hipótese do transplante e doação de órgãos sido constitucionalmente reconhecida, "[...] protege-se o bem jurídico fundamental que é a vida, compreendida em seu sentido biológico, o direito de viver humanamente, e, num sentido transcendente, de desenvolver livremente sua personalidade"15.

A Lei n. 8.489/1992 estabeleceu ainda que, no caso de doação em vida, a disposição só poderia ser efetivada se os órgãos doados fossem dúplices ou, ainda, se as partes retiradas do corpo humano não implicassem em qualquer prejuízo ou em mutilação grave ao disponente. Nesses casos, seria autorizada a doação apenas entre avós, netos, pais, filhos, irmãos, tios, sobrinhos, primos até $2^{\circ}$ grau, cunhados e cônjuges. Para tanto, o disponente deveria indicar, mediante uma autorização escrita, qual ou quais partes do corpo especificamente desejaria que fossem ou que viessem a ser objeto de doação.

Em relação ao consentimento para doação post mortem, a referida lei indicava a necessidade de consentimento expresso do doador, quando em vida, através de documento pessoal ou oficial. Sua principal inovação foi a adoção do critério da morte encefálica (ME), fundamental à persecução da certeza de morte, a fim de evitar o erro médico.

Atualmente, a Lei n. 9.434/1997, regulamentada pelo Decreto n. 2.268/1997 e posteriormente alterada pela Lei n. $10.211 / 2001^{16}$, disciplina a remoção de órgãos, tecidos e partes do corpo humano para fins de transplante e tratamento, trazendo também relevantes modificações para o ordenamento jurídico.

O texto original da Lei n. 9.434/1997, em seu artigo $4^{\circ}$, estabelecia a doação presumida de órgãos post mortem, ou seja, seria considerado doador todo aquele que não manifestasse em vida, através de anotação na Carteira de Identidade Civil ou na Carteira Nacional de Habilitação, sua condição de não doador. Era preciso, portanto, que a recusa fosse expressa em documento oficial; caso contrário, a pessoa tornar-se-ia automaticamente doadora.

Segundo esse modelo de consentimento, considerava-se, portanto, doador presumido todo indivíduo que não fizesse constar de forma indelével a condição

\footnotetext{
${ }^{14}$ ANDRADE, Taciana Palmeira. op. cit., 2009.

${ }^{15}$ BRAUNER, Maria Claudia Crespo. Ciência, biotecnologia e normatividade. Cienc. Cult., São Paulo, v. 57, n. 1, mar. 2005. Disponível em: <http://cienciaecultura.bvs.br/scielo.php?script=sci_arttext\&pid=S0009$-67252005000100017 \& \operatorname{lng}=e n \& n r m=i s o>$. Acesso em: 03 ago. 2015.

${ }^{16}$ BRASIL. Lei Federal n. 10.211, de 23 de março de 2001. Altera dispositivos da Lei no 9.434, de 4 de fevereiro de 1997, que "dispõe sobre a remoção de órgãos, tecidos e partes do corpo humano para fins de transplante e tratamento." Disponível em: <http://www.planalto.gov.br/ccivil_03/leis/LEIS_2001/ L10211.htm>. Acesso em: 29 jan. 2016.
} 
de "não doador" em documentos oficiais de identidade, permitindo-se, ainda, a reformulação da manifestação de vontade a qualquer tempo.

A mencionada lei tinha como intuito aumentar o número de doações de órgãos no país, mas não teve boa receptividade na sociedade brasileira e, segundo Almeida ${ }^{17}$, ao revés do que se esperava, "o novo contexto legal não atingiu o propósito de aumentar a oferta de órgãos; pelo contrário, milhares ou milhões se cadastraram como "não doador" em documentos oficiais".

A parca receptividade da norma pela sociedade, entretanto, contribuiu para a alteração do referido dispositivo, através da Medida Provisória (MP) n. 1718/1998, seguida pela MP n. 1.959-26/2000 e, por fim, pela edição da Lei n. 10.2112001.

Destaca-se que, na MP n. 1.959-26/2000, o critério do consentimento expresso do doador, consagrado em todas as legislações anteriores, foi resgatado, estabelecendo a subsidiariedade da decisão familiar em caso de omissão do futuro doador, constante em seu artigo $1^{\circ}$, parágrafo $6^{\circ 18}$.

A Medida Provisória aludida foi afinal revogada, já que não foi convertida em lei no prazo legal exigido.

Atualmente, o artigo $4^{\circ}$ da Lei n. 9.434/1997, alterado pela Lei n. 10.211/2001, dispõe que a família é a responsável pela decisão sobre a doação de órgãos de parentes falecidos. Não existe, portanto, amparo jurídico à manifestação de vontade do doador potencial, circunstância que revela a prevalência do monopólio de decisão familiar na hipótese de um confronto entre a vontade do doador e a vontade da própria família ${ }^{19}$.

Loureiro $^{20}$ dispõe que, em consonância com a disposição de outorgar à família o poder decisório de dispor dos órgãos e partes do corpo de ente falecido, a referida lei vetou o parágrafo único do artigo $4^{\circ}$ da Lei n. 9.434/1997, que continha o seguinte teor: "Parágrafo único. A retirada de tecidos, órgãos e partes do corpo de

\footnotetext{
${ }^{17}$ ALMEIDA, Elton Carlos de. Doação de órgãos e visão da família sobre atuação dos profissionais neste processo: revisão sistemática da literatura brasileira. 2011. Dissertação (Mestrado) - Escola de Enfermagem de Ribeirão Preto Universidade de São Paulo. Disponível em: <http://www.teses.usp.br/teses/disponiveis/22/22131/tde-19012012-105053/pt-br.php>. Acesso em: 15 abr. 2013.

18 “Na ausência de manifestação de vontade do potencial doador, o pai, a mãe, o filho ou o cônjuge poderá manifestar-se contrariamente à doação, o que será obrigatoriamente acatado pelas equipes de transplante e remoção." (destaques das autoras) BRASIL. Medida Provisória n 1.959-26, de 22 de Setembro de 2000. Altera dispositivos da Lei no 9.434, de 04 de fevereiro de 1997, que dispõe sobre a remoção de órgãos, tecidos e partes do corpo humano para fins de transplante e tratamento. Disponível em: <http://www. planalto.gov.br/ccivil_03/mpv/Antigas/1959-27.htm>. Acesso em: 21 mai. 2012.

${ }^{19}$ Art. 4을 $\mathrm{A}$ retirada de tecidos, órgãos e partes do corpo de pessoas falecidas para transplantes ou outra finalidade terapêutica dependerá da autorização do cônjuge ou parente, maior de idade, obedecida a linha sucessória, reta ou colateral, até o segundo grau, inclusive firmada em documento subscrito por duas testemunhas presentes à verificação da morte. (destaques das autoras). BRASIL. Lei ${ }^{\circ} 9.434$, de 4 de fevereiro de 1997, cit.

${ }^{20}$ LOUREIRO, Zuleica Regina de Araújo. Doador de órgãos post mortem: uma vontade sobrestada pelo Art. $4^{\circ}$ da Lei 9434/97. Brasília: FESMPDFT, 2009. Disponível em: <http://www.fesmpdft.org.br/arquivos/mono_ zuleica.pdf> Acesso em: 26 mai. 2012.
} 
pessoas falecidas poderá ser realizada a partir de registro feito em vida, pelo de cujus, nos termos do regulamento"21.

Em mensagem de veto, o legislador assim se posicionou:

Razões do veto: A inserção deste parágrafo induz o entendimento que, uma vez o potencial doador tenha registrado em vida a vontade de doação de órgãos, esta manifestação em si só seria suficiente como autorização para a retirada dos órgãos. Isto além de contrariar o disposto no caput do art. 4-- a autorização familiar contraria a prática da totalidade das equipes transplantadoras do País, que sempre consultam os familiares (mesmo na existência de documento com manifestação positiva de vontade do potencial doador) e somente retiram os órgãos se estes, formalmente, autorizarem a doação ${ }^{22}$. (destaques das autoras)

Por meio do atual artigo $4^{\circ}$ da Lei de Transplantes, as famílias dos potenciais doadores passaram a ser as únicas responsáveis pelos órgãos do ente falecido, assumindo a responsabilidade pelo destino destes. Não se prestigiou, portanto, a vontade do potencial doador, mesmo que em vida este tivesse deixado clara sua intenção, seja por documento formal ou pessoal seja por qualquer meio idôneo de manifestação.

A mudança acarretou outras discussões doutrinárias em relação aos aspectos personalíssimos da nova estrutura de consentimento. Segundo Pereira ${ }^{23}$, mais condizente com nosso sistema parece ser atualmente a aplicação do artigo 14 do Código Civil de 2002, que diz ser válida, com objetivo científico ou altruístico, a disposição gratuita do próprio corpo, no todo ou em parte, para depois da morte. Da hermenêutica depreendida de seu texto, somente na ausência da orientação do potencial doador a vontade dos parentes poderia prevalecer. Na mesma linha parece ser o entendimento de Farias $^{24}$, ao dispor que "não tendo ocorrido manifestação em vida, tal direito transmite-se para os herdeiros". Venosa também contribui ao sugerir a subsidiariedade da decisão familiar quando houver ausência de manifestação do potencial doador:

Tendo em vista o teor do art. 14 mencionado, temos que concluir, mesmo perante o sistema atual, que, enquanto não regulamentada diferentemente a disposição, será idônea qualquer manifestação de vontade escrita do doador a respeito da disposição de seus órgãos e tecidos após sua morte, devendo os parentes ou o cônjuge autorizar somente perante a omissão da pessoa falecida ${ }^{25}$.

\footnotetext{
${ }^{21}$ BRASIL. Mensagem n. 252, de 23 de março de 2001. Disponível em: <http://www.planalto.gov.br/ccivil_03/Leis/Mensagem_Veto/2001/Mv252-01.htm> Acesso em: 27 mai. 2012.

${ }^{22}$ Id. Ibid.

${ }^{23}$ PEREIRA, Caio Mário da Silva. Instituições de direito civil: introdução ao direito civil: teoria geral de direito civil. 24. ed. Rio de Janeiro: Forense. 2011. p. 188.

${ }^{24}$ FARIAS, Cristiano Chaves de. Curso de direito civil. 10. ed. Salvador: JusPodivm. 2012. p. 205.

${ }^{25}$ VENOSA, Sílvio de Salvo. Direito civil: parte geral. 11. ed. São Paulo: Atlas. 2011. p. 182.
} 
Para Marinho $^{26}$, o atual texto do artigo $4^{\circ}$ da Lei n. 9.434/1997 “[...] alija o possível doador da escolha fundamental do destino de seus órgãos e acaba por privá-lo de completa autodeterminação", pelo que defende ser necessário haver um documento legal, por escrito, que possibilite ao potencial doador manifestar, de forma livre e circunstanciada, sua vontade no sentido da doação ou não de seus órgãos.

O Decreto n. 2.268/1997, que regulamentou a Lei n. 9.434/1997, por sua vez, inova ao determinar que a retirada de tecidos, órgãos e partes do corpo humano só poderá ser realizada por equipes especializadas e em estabelecimentos de saúde, sejam eles públicos ou privados, com prévia e expressa autorização do Ministério da Saúde. A medida trouxe maior segurança à técnica dos transplantes, pois restringe tal método cirúrgico às instituições que seguem determinadas e específicas normas de procedimento.

Ademais, a lei dispõe que os transplantes somente poderão ser realizados desde que tenham sido observados todos os testes de triagem para diagnóstico de infecção e infestação, exigidos pelas normas regulamentares expedidas pelo Ministério da Saúde. Por fim, o Decreto n. 2.268/1997 vem, oportunamente, criar o Sistema Nacional de Transplante (SNT) e as Centrais de Notificação, Captação e Distribuição de Órgãos (CNCDO), integrantes do Sistema Único de Saúde (SUS), bem como a lista única nacional de receptores entre os estados da Federação.

O capítulo II da Lei n. 9.434/1997 encarregou-se de traçar os principais elementos que compõem o tema da doação post mortem. O primeiro deles está no texto do artigo $3^{\circ}$, em que se determina o critério da morte encefálica como parâmetro para a remoção de órgãos. Para que o procedimento cirúrgico seja viável, a ME deve ser constatada e registrada por dois médicos não participantes das equipes de remoção e transplante, mediante a utilização de critérios clínicos e tecnológicos definidos pelo Conselho Federal de Medicina, por meio da Resolução CFM n. 1.480/199727,28, havendo ainda a possibilidade da presença de médico de confiança da família do falecido, caso esta deseje.

A constatação inequívoca da morte do indivíduo é fundamental, segundo Diniz $^{29}$, porque, se esta não tiver sido de fato configurada, estar-se-ia retirando a vida de uma pessoa humana para que outra possa sobreviver.

\footnotetext{
${ }^{26}$ MARINHO, Alexandre. Transplantes de órgãos no Brasil. Revista de Direito Sanitário, São Paulo, v. 11, n. 3, p. 120-122, fev. 2011. Disponível em: <http://www.revistas.usp.br/rdisan/article/view/13224/15039>. Acesso em: 24 nov. 2014. http://dx.doi.org/10.11606/issn.2316-9044.v11i3p120-122.

${ }^{27}$ CONSELHO FEDERAL DE MEDICINA. Resolução n. 1.480, de 21 de agosto de 1997. Disponível em: <http://www.portalmedico.org.br/resolucoes/cfm/1997/1480_1997.htm>. Acesso em: 29 jan. 2016.

28 “....] coma aperceptivo com ausência de atividade motora supraespinal e apneia, consequência de processo irreversível e de causa conhecida, mantido por seis horas nos maiores de dois anos, corroborado por exame complementar que demonstre ausência de atividade elétrica cerebral, ou ausência de atividade metabólica cerebral, ou ausência de perfusão sanguínea cerebral, excluídos hipotermia e uso de depressores do sistema nervoso central." MARINHO, Alexandre, op. cit.

${ }^{29}$ DINIZ, Maria Helena. O estado atual do biodireito: de acordo com a Lei de Biossegurança (Lei 11.105 de 24-3-2005). 4. ed. São Paulo: Saraiva, 2007. p. 57.
} 
Entretanto, o conceito de morte encefálica ainda é pouco compreendido pela população em geral, dada a dificuldade em considerar a morte quando ainda subsistem batimentos cardíacos, pois culturalmente esta é representada como a parada de todas as funções do $\operatorname{corpo}^{30}$. Essa incompreensão popular, segundo Almeida ${ }^{31}$, constitui um dos vários motivos que levam à recusa por parte da família quanto à doação dos órgãos do parente falecido.

O legislador estabelece, ainda, a obrigação dos médicos responsáveis pelo procedimento cirúrgico de recompor condignamente o de cujus para ser entregue, em seguida, aos parentes do morto ou seus responsáveis legais para sepultamento.

Sobre o dever de recomposição do doador pela equipe médica especializada, Bendassolli2 aponta que, por desconhecimento do procedimento legal e pelo preconceito sobre o processo, durante a entrevista familiar sobre a doação dos órgãos do ente falecido, a família costuma associar a doação à mutilação ou destruição do corpo após a morte, o que constitui um dos fatores responsáveis pela recusa familiar para doação.

Em ordem cronológica, o diploma normativo seguinte a tratar da matéria do transplante de órgãos foi a Lei n. 10.406/2002, que instituiu o atual Código Civil brasileiro, no capítulo sobre os direitos da personalidade, artigo 14 e parágrafo único:

Art. 14. É válida, com objetivo científico, ou altruístico, a disposição gratuita do próprio corpo, no todo ou em parte, para depois da morte.

Parágrafo único. $\mathrm{O}$ ato de disposição pode ser livremente revogado a qualquer tempo ${ }^{33}$.

A lei civil ratifica os ditames constitucionais, ao permitir a disposição do corpo em vida e após a morte, desde que gratuita. Além disso, resgata o direito personalíssimo de disposição do corpo pelo próprio doador, estabelecido em todas as legislações anteriores à Lei n. 9.434/1997.

Na esteira do tema dos transplantes, nota-se que o Código Civil reconhece a importância da elevação dos direitos personalíssimos como forma de se respeitar a

\footnotetext{
${ }^{30}$ MORAES, Edvaldo Leal. A recusa familiar no processo de doação de órgãos e tecidos para transplante. 2010. Dissertação (Mestrado) - Escola de Enfermagem, Universidade de São Paulo, 2010. Disponível em: <http://www. teses.usp.br/teses/disponiveis/7/7131/tde-13072007-092002/pt-br.php>. Acesso em: 15 abr. 2013; LAMB, David. Transplantes de órgãos e ética. Tradução de Jorge Curbelo. São Paulo: Sobravime; Ed. Hucitec, 2000.

${ }^{31}$ ALMEIDA, Elton Carlos de. op. cit.

${ }^{32}$ BENDASSOLLI, Pedro Fernando. Percepção do corpo, medo da morte, religião e doação de órgãos. Psicol. Reflex. Crit., Porto Alegre, v. 14, n. 1, 2001. Disponível em <http://www.scielo.br/scielo. php?script=sci_arttext\&pid=S0102-79722001000100019\&Ing=pt\&nrm=iso>. Acesso em: 12 nov. 2014. http://dx.doi.org/10.1590/S0102-79722001000100019.

${ }^{33}$ BRASIL. Lei Federal n. 10.406, de 10 de janeiro de 2002. Institui o Código Civil.. Disponível em: <http://www.planalto.gov.br/ccivil_03/leis/2002/I10406.htm>. Acesso em: 29 de jan. 2016.
} 
autonomia da vontade daqueles que pretendem ser doadores de órgãos, para depois da morte. Para Venosa ${ }^{34}$, “[...] a faculdade de doar órgãos após a morte é direito potestativo da pessoa [...]"; trata-se, portanto, de poderes que cada um deve exercer sobre si mesmo. Assim dispondo, valoriza a autonomia do ser humano enquanto sujeito capaz de autodeterminar suas escolhas quanto a seu corpo.

Frente à polêmica divergência interpretativa do atual artigo $4^{\circ}$ da Lei n. 9.434/1997 e do artigo 14 do Código Civil, o Conselho da Justiça Federal (CJF), na IV Jornada de Direito Civil, editou o Enunciado 277, in verbis:

277 - Art. 14: O art. 14 do Código Civil, ao afirmar a validade da disposição gratuita do próprio corpo, com objetivo científico ou altruístico, para depois da morte, determinou que a manifestação expressa do doador de órgãos em vida prevalece sobre a vontade dos familiares, portanto, a aplicação do art. $4^{\circ}$ da Lei n. 9.434/97 ficou restrita à hipótese de silêncio do potencial doador $^{35}$. (destaques das autoras)

Conforme tal orientação normativa, ao afirmar a validade da disposição gratuita do próprio corpo para depois da morte, o diploma civil teria determinado que a manifestação expressa do doador de órgãos em vida sobrepõe-se à vontade dos familiares, ficando a aplicação do artigo $4^{\circ}$ da Lei n. 9.434/1997 adstrita aos casos em que o potencial doador restou silente. Na acepção de Diniz ${ }^{36}$, a aplicação do artigo $4^{\circ}$ da Lei n. 9.434/1997 estaria restrita, portanto, à hipótese de silêncio do potencial doador. $\mathrm{O}$ doador em transplante post mortem seria aquele que não manifestasse em vida vontade contrária, ou aquele cujo cônjuge ou parente em linha reta ou colateral até o segundo grau consentisse na retirada de seus órgãos.

Caracterizado o impasse legislativo e demonstrado o posicionamento majoritário da doutrina em privilegiar a vontade manifesta do doador potencial em vida sobre o desejo familiar, é necessário estabelecer a forma em que essa manifestação pode se expressar e produzir efeitos jurídicos.

Com o advento da Resolução do Conselho Federal de Medicina n. 1995/2012 $2^{37}$, que disciplinou as denominadas Diretivas Antecipadas de Vontade (DAVs), uma nova perspectiva para a discussão dos conflitos do consentimento para doação de órgãos se instituiu.

\footnotetext{
${ }^{34}$ VENOSA, Sílvio de Salvo. op. cit., p. 181.

${ }^{35}$ BRASIL. Conselho da Justiça Federal. IV Jornada de Direito Civil. 2007. Organização: Ministro Ruy Rosado de Aguiar Jr. Brasília: CJF, 2007. 2 v. Disponível em: <http://columbo2.cjf.jus.br/portal/publicacao/download.wsp?tmp.arquivo=2016>. Acesso em: 23 mai. 2012.

${ }^{36}$ DINIZ, Maria Helena. op. cit., p. 57.

${ }^{37}$ CONSELHO FEDERAL DE MEDICINA. Resolução n. 1995, de 09 de agosto de 2012. Dispõe sobre as diretivas antecipadas de vontade dos pacientes. Disponível em: <http://www.cremesp.org.br/?siteAcao=Pe squisaLegislacao\&dif=s\&ficha=1\&id=10938\&tipo=RESOLU\%C7\%C30\&orgao=Conselho\%20Federal\%20 de\%20Medicina\&numero=1995\&situacao=VIGENTE\&data=09-08-2012>. Acesso em: 29 jan. 2016.
} 
Trata-se de orientação segundo a qual, nos termos de seu artigo $1^{0^{38}}$, nas decisões sobre cuidados e tratamentos de pacientes que se encontram incapazes de se comunicar, ou de expressar de maneira livre e independente suas vontades, o médico deverá levar em consideração as eventuais diretivas antecipadas de vontade deixadas pelo paciente ${ }^{39}$.

Conforme Marinele ${ }^{40}$, não tendo a mencionada resolução estabelecido uma forma específica de expressar as diretivas antecipadas de vontade, essa forma seria livre, podendo-se optar por documento escrito, público ou particular, desde que comprovada a autenticidade da assinatura: cartas redigidas de próprio punho, ainda que não assinadas: vídeos, quando possível com identificação da data da produção; ou mesmo por declaração verbal, desde que feita diretamente ao médico e anotada no prontuário do paciente ${ }^{41}$, nos termos do artigo $2^{\circ}$, parágrafo $4^{\circ}$ da Resolução CFM n. 1995/2012.

Ademais, conforme artigo $2^{\circ}$, parágrafos $3^{\circ}$ e $5^{\circ}$ da mencionada Resolução ${ }^{42}$, a decisão familiar quanto ao tratamento dispensado ao paciente terminal somente é levada em consideração caso este já esteja impossibilitado de manifestar sua vontade.

Asseveram Goiatá e Naves ${ }^{43}$ que as DAVs constituem um eficiente meio de determinação da vontade do indivíduo que opta por doar ou não seus órgãos, devendo essa decisão predominar sobre a vontade dos familiares.

Noutro sentido, Dadalto, Tupinambás e Greco $^{44}$ discorrem que as diretivas não teriam incluído a hipótese de aplicação em caso de doação de órgãos, presentes

\footnotetext{
38 “Art. $1^{\circ}[\ldots]$ o conjunto de desejos, prévia e expressamente manifestados pelo paciente, sobre cuidados e tratamentos que quer, ou não, receber no momento em que estiver incapacitado de expressar, livre e autonomamente, sua vontade." CONSELHO FEDERAL DE MEDICINA. Resolução n. 1995, de 09 de agosto de 2012, cit.

${ }^{39}$ MARINELE, Marcelo Romão. A declaração de vontade do paciente terminal. As diretivas antecipadas de vontade à luz da Resolução 1995/2012 do Conselho Federal de Medicina. Jus Navegandi, out. 2013. Disponível em: <http://jus.com.br/artigos/25636/a-declaracao-de-vontade-do-paciente-terminal/2\#ixzz3fgweBMIG>. Acesso em: 29 jul. 2015.

${ }^{40}$ Id. Ibid.

${ }^{41}$ NUNES, Maria Inês; ANJOS, Márcio Fabri dos. Diretivas antecipadas de vontade: benefícios, obstáculos e limites. Rev. Bioét., Brasília, v. 22, n. 2, p. 241-251, ago. 2014. Disponível em <http://www.scielo.br/scielo. php?script=sci_arttext\&pid=S1983-80422014000200006\&lng=pt\&nrm=iso >. Acesso em: 03 ago. 2015. http://dx.doi.org/10.1590/1983-80422014222005.

${ }^{42}$ Artigo $2^{\circ}$, " $\S 3^{\circ}$ As diretivas antecipadas do paciente prevalecerão sobre qualquer outro parecer não médico, inclusive sobre os desejos dos familiares; [...] $\S 5^{\circ}$ Não sendo conhecidas as diretivas antecipadas de vontade do paciente, nem havendo representante designado, familiares disponíveis ou falta de consenso entre estes, o médico recorrerá ao Comitê de Bioética da instituição, caso exista, ou, na falta deste, à Comissão de Ética Médica do hospital ou ao Conselho Regional e Federal de Medicina para fundamentar sua decisão sobre conflitos éticos, quando entender esta medida necessária e conveniente." CONSELHO FEDERAL DE MEDICINA. Resolução n. 1995, de 09 de agosto de 2012, cit.

${ }^{43}$ GOIATÁ, Sarah Rêgo; NAVES, Bruno Torquato de Oliveira. As diretivas antecipadas de vontade na política de doação de órgãos. Jus Navegandi, nov. 2014. Disponível em: <http://jus.com.br/artigos/33626/as-diretivas-antecipadas-de-vontade-na-politica-de-doacao-de-orgaos>. Acesso em: 01 ago. 2015.

${ }^{44}$ DADALTO, Luciana; TUPINAMBÁS, Unai; GRECO, Dirceu Bartolomeu. Diretivas antecipadas de vontade: um modelo brasileiro. 2013. Disponível em: <http://www.scielo.br/pdf/bioet/v21n3/a11v21n3.pdf>. Acesso em: 25 jul. 2015. http://dx.doi.org/10.1590/S1983-80422013000300011.
} 
nos modelos estadunidenses e espanhóis. Os mesmos fundamentam tal posição sob o argumento de que a Resolução iria de encontro à atual Lei de Transplantes, que determinou a necessidade de autorização familiar para a doação. Explicam, ainda, que, no caso da doação de órgãos, o uso da DAV

[...] geraria choque de institutos e, além disso, desnaturaria as DAVs, haja vista que são, por essência, negócio jurídico, com efeito inter vivos, cujo principal objeto é garantir a autonomia do sujeito quanto aos tratamentos a que será submetido em caso de terminalidade da vida ${ }^{45}$.

Sobre a inclusão das doações de órgão como uma das hipóteses de utilização das diretivas, Dadalto ${ }^{46}$ também explica não ser possível no ordenamento brasileiro, por ir de encontro aos termos da Lei n. 9.434/1997.

Dadalto $^{47}$ ressalta, ainda, que apesar da doutrina estrangeira admitir que a DAV do paciente terminal possa conter declaração acerca de doação de órgãos, considerando-a como decisão de cunho personalíssimo, no Brasil isso não é possível por contrariar a legislação específica, que estabeleceu o monopólio da decisão familiar sobre a questão.

Vê-se, portanto, que o maior fator impeditivo para a extensão do uso das DAVs como instrumento de formalização do desejo do potencial doador de órgãos no Brasil são os termos do artigo $4^{\circ}$ da atual Lei de Transplantes, objeto de discussão no presente estudo.

Feitos tais esclarecimentos, nota-se que a tendência interpretativa doutrinária em face do conflito existente entre o disposto no artigo 14 do diploma civil e o artigo $4^{\circ}$ da Lei n. 9.434/1997 é de reverenciar a autonomia individual de cada pessoa humana sobre aspectos de sua existência e para depois desta. Dessa forma, não se pode ignorar a coexistência no ordenamento brasileiro de dois dispositivos de lei que tratam da matéria do consentimento para a doação. Se, no entanto, apenas a ordem emanada da Lei de Transplantes for privilegiada, estar-se-ão lesando direitos individuais fundamentais ao pleno exercício dos direitos personalíssimos.

\footnotetext{
${ }^{45}$ Id. Ibid.

46، [...] o Direito Comparado nos apresenta que no conteúdo das diretivas antecipadas tem sido aceita a disposição sobre doação de órgãos. Mas a doação de órgãos no Brasil já está regulada pela Lei 9.434/97, alterada pela Lei 10.211/01, bastando que, para a efetivação da doação, seus ditames sejam seguidos. Entre eles, a autorização do cônjuge ou de parente maior de idade, obedecida a linha sucessória, o que não seria admissível nas diretivas antecipadas, vez que expressa a vontade autônoma do paciente." DADALTO, Luciana. Reflexos jurídicos da Resolução CFM 1.995/12. Rev bioét., v. 21, n. 1, p. 106-112, 2013. Disponível em: <http://www.scielo.br/pdf/bioet/v21n1/a12v21n1>. Acesso em: 01 ago. 2015

${ }^{47}$ DADALTO, Luciana. Distorções acerca do testamento vital no Brasil (ou o porquê é necessário falar sobre uma declaração prévia de vontade do paciente terminal). Rev. Bioéticay Derecho, Barcelona, n. 28, mayo 2013. Disponivel em: <http://scielo.isciii.es/scielo.php?script=sci_arttext\&pid=S1886-58872013000200006\&lng =es\&nrm=iso>. Acesso em: 04 ago. 2015. http://dx.doi.org/10.4321/S1886-58872013000200006.
} 
Entretanto, sabendo-se do papel fundamental da família no atual processo de doação de órgãos, em que ela tem a responsabilidade pela decisão sobre o destino dos órgãos do parente falecido, é importante tecer algumas considerações a respeito do momento da morte e sua repercussão na unidade familiar.

\section{A família no processo de doação de órgãos}

A morte de um ente querido é quase sempre um momento traumático e delicado para a família, quando se imiscuem sentimentos como dor, medo, desespero, raiva e angústia. Quase que instantaneamente ao diagnóstico de morte encefálica, a família deve ser entrevistada para saber sua decisão quanto à doação de órgãos do parente falecido, devido à rápida deterioração dos órgãos após a morte, que pode inviabilizar o transplante.

A pressa exigida na decisão familiar sobre a doação, segundo Cajado ${ }^{48}$, pode antecipar uma decisão imatura, permeada de impasses subjetivos. Para a autora, tais fatores, quando não trabalhados, podem contribuir para a negativa familiar quanto à doação de órgãos, tecidos e partes do corpo para transplante.

Concordam Rech e Rodrigues Filho ${ }^{49}$ que "a entrevista familiar é um momento delicado no processo de doação, porque concretiza para a família a morte, a separação e a impotência”.

Para Loureiro, nesse momento do processo de doação:

Sentimentos antagônicos eclodem simultaneamente, negar e aceitar a morte, preservar a integridade física do morto e oferecer seus órgãos para salvar vidas de terceiros, pessoas desconhecidas, que estão à espera de um gesto humanitário da parte de alguém que acaba de sofrer uma lesão emocional intensa ${ }^{50}$.

No mesmo sentido, Santos ${ }^{51}$ ressalva que a família reflete parcialmente sobre a situação que vivencia com a morte do parente, e isso influencia diretamente o resultado da entrevista quanto à doação. Bittencourt, Quintana e Velho ${ }^{52}$

\footnotetext{
${ }^{48}$ CAJADO, Maria Constância Velloso. Doar ou não doar, eis a questão: impasses subjetivos no processo de doação de órgãos e tecidos para transplante. 2011. 202 f. Dissertação (Mestrado em Direito) - Programa de Pós-Graduação em Família na Sociedade Contemporânea da Universidade Católica do Salvador, Salvador, 2011. ${ }^{49} \mathrm{RECH}$, Tatiana H.; RODRIGUES, Édson Moraes. op. cit.

${ }^{50}$ LOUREIRO, Zuleica Regina de Araújo. op. cit.

${ }^{51}$ SANTOS, Marcelo José dos. A entrevista familiar no processo de doação de órgãos e tecidos para transplante. Dissertação (Mestrado) - Escola de Enfermagem, Universidade de São Paulo, 2010. Disponível em: <http://www.teses.usp.br/teses/disponiveis/7/7136/tde-20052010-105423/pt-br.php>. Acesso em: 15 abr. 2013.

${ }^{52}$ BITTENCOURT, Ana Luiza Portela; QUINTANA, Alberto Manuel; VELHO, Maria Teresa Aquino de Campos. A perda do filho: luto e doação de órgãos. Estud. psicol., Campinas, v. 28, n. 4, dez. 2011. Disponível em <http://www.scielo.br/scielo.php?script=sci_arttext\&pid=S0103-166X2011000400004\&lng=pt\&nrm=iso>. Acesso em: 12 nov. 2014. http://dx.doi.org/10.1590/S0103-166X2011000400004.
} 
elucidam que é preciso que a família receba informações pertinentes e adequadas sobre o processo de doação, que possibilitem a tomada de decisão de maneira voluntária, livre de pressões externas. Nota-se que, entre a declaração de ME e a entrevista familiar, existe um caminho que, apesar de curto, é igualmente complexo e delicado.

Nessa linha, Cajado ${ }^{53}$ cita como fatores complicadores do procedimento: os conflitos familiares, a falta de informação sobre o desejo do paciente em vida, a desconfiança sobre o processo, as dificuldades de compreensão da morte encefálica e impasses subjetivos.

No mesmo sentido, Moraes e Massaroll ${ }^{54}$ apontam como motivos da recusa familiar para doação de órgãos e tecidos para transplante: a crença religiosa; a espera de um milagre; a não compreensão do diagnóstico de ME e a crença na reversão do quadro; a recusa da manipulação do corpo; o medo da reação da família; a inadequação da informação e a ausência de confirmação da ME; a desconfiança na assistência e o medo do comércio de órgãos; a inadequação no processo de doação; o desejo do paciente falecido, manifestado em vida, de não ser um doador de órgãos; e o medo da perda do ente querido.

Diante das dificuldades encontradas no processo de entrevista familiar, a recusa da família quanto à doação de órgãos do ente falecido vem sendo considerada um dos fatores responsáveis pela escassez de órgãos e tecidos para transplante ${ }^{55}$.

Dados da Associação Brasileira de Transplantes de Órgãos (ABTO) confirmam essa realidade. Segundo a entidade, a não concretização da doação de órgãos por potenciais doadores notificados, do total de 2.214 de notificações nos estados brasileiros durante o primeiro trimestre de 2014, teve como causas: recusa de doação na entrevista familiar em 638 (47\%) dos casos; contraindicação médica (CIM) em 306 (14\%); parada cardiorrespiratória (PCR) em 294 (13\%); e por outros motivos em 367 (16\%) dos casos $^{56}$.

Por outro lado, um dos pontos que favorecem a decisão positiva quanto à doação de órgãos pela família perpassa um aspecto moral, ao entender o ato como uma ação que pode salvar a vida de outras pessoas, ajudando a dar

\footnotetext{
${ }^{53}$ CAJADO, Maria Constância Velloso. op. cit.

${ }^{54}$ MORAES, Edvaldo Leal de; MASSAROLLO, Maria Cristina Komatsu Braga. Recusa de doação de órgãos e tecidos para transplante relatados por familiares de potenciais doadores. Rev. Acta Paulista de Enfermagem, São Paulo, v. 22, n. 2. 2009. Disponível em: <http://www.scielo.br/pdf/ape/v22n2/a03v22n2.pdf>. Acesso em: 30 mai. 2012. http://dx.doi.org/10.1590/S0103-21002009000200003.

${ }^{55}$ ROSARIO, Elza Nascimento do et al. Recusa familiar diante de um potencial doador de órgãos. Cad. saúde colet., Rio de Janeiro, v. 21, n. 3, set. 2013. Disponível em <http://www.scielo.br/scielo. php?script=sci_arttext\&pid=S1414-462X2013000300005\&lng=pt\&nrm=iso>. Acesso em: 12 nov. 2014. http://dx.doi.org/10.1590/S1414-462X2013000300005.

${ }^{56}$ ABTO. op. cit.
} 
significado à vida e à morte do ente querido e minimizando a dor e o sofrimento durante o processo de luto ${ }^{57}$.

Outro fator decisivo para a diminuição da recusa familiar é a capacitação dos profissionais responsáveis pela abordagem da família. Conforme sinaliza Bousso, os profissionais de saúde têm o papel fundamental de reconhecimento do sofrimento e de acolhimento da família ${ }^{58}$.

Nesse sentido, Lira et al..$^{59}$ destacam que as relações entre profissionais de saúde e paciente e família interferem no processo de doação de órgãos, na medida em que as famílias, sentindo a mecanicidade, o distanciamento da equipe, a falta de comprometimento, a falta de aceitação e elucidação dos profissionais de saúde, prontamente respondem com a negação da doação de órgãos porque não conseguem dissociar sua decisão do tratamento recebido.

Ojo, Heinrichs, Emond et al..$^{60}$ destacam que o entrevistador deve proporcionar um ambiente confortável para a família decidir, de modo que seus membros não se sintam pressionados a doar, muito menos culpados por não doar.

Bousso assevera, ainda, que:

[...] quando o contexto promove a aceitação do sofrimento, acolhe dúvidas, proporciona tempo para a família compartilhar ideias e sentimentos, facilita o acesso ao suporte social, oferece as informações necessárias, a família pode caminhar por uma trajetória de recuperação na qual o processo de decisão acontece com menos conflito ${ }^{61}$.

Bittencourt, Quintana e Velho ressaltam a importância de a família ser acompanhada pelos profissionais de saúde também após a captação dos órgãos do parente falecido, a fim de que seja acolhida em suas dúvidas e angústias e, caso necessário, encaminhada para serviços especializados de acompanhamento psicológico, pois o “[...] abandono da família após a captação parece deixar os

\footnotetext{
${ }^{57}$ BOUSSO, Regina Szylit. O processo de decisão familiar na doação de órgãos do filho: uma teoria substantiva. Texto contexto - enferm., Florianópolis, v. 17, n. 1, mar. 2008. Disponível em <http://www.scielo.br/ scielo.php?script=sci_arttext\&pid=S0104-07072008000100005\&lng=pt\&nrm=iso >. Acesso em: 12 nov. 2014. http://dx.doi.org/10.1590/S0104-07072008000100005.

${ }^{58}$ Id. Ibid.

${ }^{59}$ LIRA, Gerlene Grudka et al. Family considerations about the decision to refuse organ donation. Acta paul. enferm., São Paulo, v. 25, n. esp. 2, 2012. Disponível em <http://www.scielo.br/scielo. php?script=sci_arttext\&pid=S0103-21002012000900022\&lng=pt\&nrm=iso>. Acesso em: 12 nov. 2014. http://dx.doi.org/10.1590/S0103-21002012000900022.

${ }^{60}$ OJO, Akinlolu O.; HEINRICHS, Dennis; EMOND, Jean C.; MCGOWAN, Joshua J., GUIDINGER, Mary K.; DELMONICO, Francis L.; METZGER, Robert A. Organ donation and utilization in the USA. American Journal of Transplantation, v. 4, suppl, 9, p. 27-37, 2004. Disponivel em: <http://onlinelibrary.wiley.com/ doi/10.1111/j.1600-6135.2004.00396.x/pdf>. Acesso em: 17 nov. 2014.

${ }^{61}$ BOUSSO, Regina Szylit. op. cit.
} 
familiares com o sentimento de que foram usados e de que foi violado o corpo de seu filho por interesse"62.

Deve-se levar em conta que a família do potencial doador encontra-se fragilizada e vivenciando um momento delicado e conflituoso, decorrente do processo de luto, em que o processo de doação de órgãos não pode ter como objetivo somente a própria doação, mas a assistência à família, voltada a seu acolhimento e não ao convencimento quanto à doação ou não dos órgãos do ente falecido ${ }^{63}$.

Diante desse fato social, muitas questões delicadas devem ser levadas em consideração no processo de autorização do transplante, o que conduz ao entendimento de que a atribuição familiar de deter o exclusivo poder decisório sobre a doação de órgãos de parentes falecidos, ignorando a vontade expressa do doador, pode não ser a melhor opção para as demandas do Sistema Nacional de Transplantes.

\section{Considerações finais}

Há muito tempo o destino do corpo morto deixou de ser apenas o sepultamento ou a cremação. A evolução científica permitiu que seus órgãos, tecidos e partes pudessem salvar vidas e renovar esperanças, proporcionando a pacientes sem perspectivas de melhoras uma nova chance de viver dignamente.

O Brasil passa hoje por uma fase otimista no âmbito da Política Nacional de Transplantes, mantendo-se como o maior sistema público de transplantes do mundo, com 95\% das cirurgias feitas pelo Sistema Único de Saúde ${ }^{64}$. Apesar de tamanho empenho, ainda são muitas as pessoas que aguardam por órgãos no País, já que o número de doadores é incompatível com o de receptores.

A legislação sobre o tema de doação e transplante de órgãos, diante dessa realidade, tem o dever de prezar não só pela garantia da integridade e dignidade físicas da pessoa humana, como também de facilitar a captação e distribuição de órgãos no Brasil, de modo a impactar no principal empecilho para a doação transplante de órgãos - que é a autorização da família.

Entretanto, subsiste no direito brasileiro um conflito legislativo, ainda sem solução legal, a respeito de quem detém o poder de decidir sobre doação e transplante de órgãos de pessoa falecida, uma vez que a legislação específica sobre transplantes no Brasil concentrou a responsabilidade pelo destino dos órgãos do de cujus nas mãos da família, em dissonância com os termos do atual Código Civil.

\footnotetext{
${ }^{62}$ BITTENCOURT, Ana Luiza Portela; QUINTANA, Alberto Manuel; VELHO, Maria Teresa Aquino de Campos. op. cit. ${ }^{63}$ PESSOA, João Luis Erbs; SCHIRMER, Janine; ROZA, Bartira de Aguiar. Avaliação das causas de recusa familiar a doação de órgãos e tecidos. Acta paul. enferm., São Paulo, v. 26, n. 4, 2013. Disponível em <http:// www.scielo.br/scielo.php?script=sci_arttext\&pid=S0103-21002013000400005\&lng=pt\&nrm=iso $>$. Acesso em: 12 nov. 2014. http://dx.doi.org/10.1590/S0103-21002013000400005.

${ }^{64}$ BRASIL bate recorde em doação de órgãos. Ministério da Saúde, 2011, cit.
} 
Diante do conflito entre leis que coexistem no sistema normativo, o Enunciado número 277 do Conselho da Justiça Federal reconheceu a titularidade do sujeito sobre o próprio corpo, devolvendo ao doador o poder de dispor de seu corpo da forma como escolher em vida, reservando à família o direito de decidir quando ausente qualquer manifestação de vontade daquele. Trata-se, todavia, apenas de orientação doutrinária, subsistindo o conflito legal, ainda pendente de solução jurídica.

É necessária uma adequação entre os dispositivos de lei, partindo-se do texto já existente do artigo $4^{\circ}$ da Lei n. 9.434/1997 e introduzindo, apenas, em respeito aos direitos fundamentais da pessoa humana, a manifestação da vontade do doador, ainda em vida, devidamente documentada. A doação de órgãos é um ato de solidariedade que deve ocorrer por vontade do próprio doador, dado seu caráter incontestavelmente personalíssimo. O desrespeito à sua vontade pela família constitui evidente lesão aos direitos individuais ${ }^{65}$.

Enquanto a legislação brasileira sobre doação e transplante de órgão se mantiver conflituosa com os interesses daqueles que necessitam de órgãos para sobreviver, cabe, sobretudo ao poder público, promover campanhas para informação e conscientização popular sobre a importância da doação de órgãos como medidas direcionadas ao aumento do número de doadores, além do desenvolvimento/ inclusão da temática de doação de órgãos na Política de Educação Permanente dos profissionais de saúde para que desenvolvam habilidades para lidar com essa situação tão complexa.

Nesse sentido, em face do contexto sociolegal em que se encontra o país - e considerando-se que o processo atual de doação de órgãos depende exclusivamente da autorização da família -, é necessário também incentivar as pessoas a manifestarem seu desejo quanto à doação de órgãos aos seus familiares, como forma de diminuir os índices de recusa familiar ${ }^{66}$.

Acredita-se que tais medidas possam contribuir para o aumento nos índices de doadores potenciais e efetivos, refletindo positivamente no número de transplantes de órgãos - o que, consequentemente, representa a sobrevida de milhares de pessoas que atualmente estão em filas de espera por um transplante. No tensionamento entre o início e o fim, a doação de órgãos reafirma a possibilidade solidária do compromisso com a vida.

\footnotetext{
${ }^{65}$ LOUREIRO, Zuleica Regina de Araújo. op. cit.

${ }^{66}$ DALBEM, Giana Garcia; CAREGNATO, Rita Catalina Aquino. Doação de órgãos e tecidos para transplante: recusa das famílias. Texto contexto - enferm., Florianópolis, v. 19, n. 4, dez. 2010. Disponível em <http:// www.scielo.br/scielo.php?script=sci_arttext\&pid=S0104-07072010000400016\&lng=pt\&nrm=iso $>$. Acesso em: 04 nov. 2014. http://dx.doi.org/10.1590/S0104-07072010000400016.
} 


\section{Referências}

ABADIE, Alberto; GAY, Sebastien. The impact of presumed consent legislation on cadaveric organ donation: a cross country study. J Healthy Econ. v. 25, n. 4, p. 599-620, Dec. 2005. Disponível em: <http://www.ksg.harvard.edu/fs/aabadie/pconsentp.pdf $>$. Acesso em: 26 nov. 2014. 10.1016/j.jhealeco.2006.01.003.

ABTO. Relatório Brasileiro de Transplantes, ano 20, n. 1, 2014. Disponível em: <http://www. abto.org.br/abtov03/Upload/file/RBT/2014/rbt2014parc-jan-mar.pdf> Acesso em: 10 nov. 2014.

ALMEIDA, Elton Carlos de. Doação de órgãos e visão da família sobre atuação dos profissionais neste processo: revisão sistemática da literatura brasileira. 2011. Dissertação (Mestrado) Escola de Enfermagem de Ribeirão Preto Universidade de São Paulo. Disponível em: $<$ http:// www.teses.usp.br/teses/disponiveis/22/22131/tde-19012012-105053/pt-br.php >. Acesso em: 15 abr. 2013.

ANDRADE, Taciana Palmeira. Doação de órgãos post mortem: a viabilidade de adoção pelo sistema brasileiro da escolha pelo doador do destinatário dos seus órgãos. 2009. Programa de Pós-Graduação em Direito - Faculdade de Direito. Universidade Federal da Bahia, Salvador, 2009. Disponível em <https://repositorio.ufba.br/ri/bitstream/ri/12492/1/TACIANA\%20 PALMEIRA\%20ANDRADE.pdf >. Acesso em: 20 nov. 2014.

BENDASSOLLI, Pedro Fernando. Percepção do corpo, medo da morte, religião e doação de órgãos. Psicol. Reflex. Crit., Porto Alegre, v. 14, n. 1, 2001. Disponível em <http://www. scielo.br/scielo.php?script=sci_arttext\&pid=S0102-79722001000100019\&lng=pt\&nrm=iso $>$. Acesso em: 12 nov. 2014. http://dx.doi.org/10.1590/S0102-79722001000100019.

BITTENCOURT, Ana Luiza Portela; QUINTANA, Alberto Manuel; VELHO, Maria Teresa Aquino de Campos. A perda do filho: luto e doação de órgãos. Estud. psicol., Campinas, v. 28 , n. 4, dez. 2011. Disponível em <http://www.scielo.br/scielo.php?script=sci arttext\&pid=S0103-166X2011000400004\&lng=pt\&nrm=iso $>$. Acesso em: 12 nov. 2014. http://dx.doi.org/10.1590/S0103-166X2011000400004.

BOUSSO, Regina Szylit. O processo de decisão familiar na doação de órgãos do filho: uma teoria substantiva. Texto contexto - enferm., Florianópolis, v. 17, n. 1, mar. 2008. Disponível em $<$ http://www.scielo.br/scielo.php?script=sci_arttext\&pid=S0104-07072008000100005\&lng=p t\&nrm=iso >. Acesso em: 12 nov. 2014. http://dx.doi.org/10.1590/S0104-07072008000100005.

BRASIL bate recorde em doação de órgãos. Ministério da Saúde, 2011. Disponível em: $<$ http:// portal.saude.gov.br/portal/aplicacoes/noticias/default.cfm?pg=dspDetalheNoticia\&id_ area $=124 \&$ CO_NOTICIA=12289> Acesso em: 23 mai. 2012.

BRASIL. Conselho da Justiça Federal. IV Jornada de Direito Civil. 2007. Organização: Ministro Ruy Rosado de Aguiar Jr. Brasília: CJF, 2007. 2 v. Disponível em: <http://columbo2.cjf.jus.br/ portal/publicacao/download.wsp?tmp.arquivo=2016>. Acesso em: 23 mai. 2012.

. Constituição da República Federativa do Brasil. VadeMecum Compacto. 4. ed. São Paulo. Saraiva, 2010. 1544 p. 
BRASIL. Mensagem no 252, de 23 de março de 2001. Disponível em: <http://www.planalto. gov.br/ccivil_03/Leis/Mensagem_Veto/2001/Mv252-01.htm> Acesso em: 27 mai. 2012.

BRAUNER, Maria Claudia Crespo. Ciência, biotecnologia e normatividade. Cienc. Cult., São Paulo, v. 57, n. 1, mar. 2005. Disponível em: <http://cienciaecultura.bvs.br/scielo.php?script=sci_ arttext\&pid=S0009-67252005000100017\&lng=en\&nrm=iso > . Acesso em: 03 ago. 2015.

CAJADO, Maria Constância Velloso. Doar ou não doar, eis a questão: impasses subjetivos no processo de doação de órgãos e tecidos para transplante. 2011. 202 f. Dissertação (Mestrado em Direito) - Programa de Pós-Graduação em Família na Sociedade Contemporânea da Universidade Católica do Salvador, Salvador, 2011.

DADALTO, Luciana. Distorções acerca do testamento vital no Brasil (ou o porquê é necessário falar sobre uma declaração prévia de vontade do paciente terminal). Rev. Bioética y Derecho, Barcelona, n. 28, mayo 2013. Disponível em: <http://scielo.isciii.es/scielo.php?script=sci_ arttext\&pid=S1886-58872013000200006\&lng=es\&nrm=iso $>$. Acesso em: 04 ago. 2015. http://dx.doi.org/10.4321/S1886-58872013000200006.

Reflexos jurídicos da Resolução CFM 1.995/12. Rev bioét., v. 21, n. 1, p. 106-112, 2013. Disponível em: <http://www.scielo.br/pdf/bioet/v21n1/a12v21n1>. Acesso em: 01 ago. 2015.

; TUPINAMBÁS, Unai; GRECO, Dirceu Bartolomeu. Diretivas antecipadas de vontade: um modelo brasileiro. 2013. Disponível em: <http://www.scielo.br/pdf/bioet/v21n3/a11v21n3. pdf>. Acesso em: 25 jul. 2015. http://dx.doi.org/10.1590/S1983-80422013000300011.

DALBEM, Giana Garcia; CAREGNATO, Rita Catalina Aquino. Doação de órgãos e tecidos para transplante: recusa das famílias. Texto contexto - enferm., Florianópolis, v. 19, n. 4, dez. 2010. Disponível em <http://www.scielo.br/scielo.php?script=sci arttext\&pid=S0104-07072010000400016\&lng=pt\&nrm=iso $>$. Acesso em: 04 nov. 2014. http://dx.doi.org/10.1590/S0104-07072010000400016.

DINIZ, Maria Helena. O estado atual do biodireito: de acordo com a Lei de Biossegurança (Lei 11.105 de 24-3-2005). 4. ed. São Paulo: Saraiva, 2007.

FARIAS, Cristiano Chaves de. Curso de direito civil. 10. ed. Salvador: JusPodivm. 2012.

GOIATÁ, Sarah Rêgo; NAVES, Bruno Torquato de Oliveira. As diretivas antecipadas de vontade na política de doação de órgãos. Jus Navegandi, nov. 2014. Disponível em: <http:// jus.com.br/artigos/33626/as-diretivas-antecipadas-de-vontade-na-politica-de-doacao-deorgaos>. Acesso em: 01 ago. 2015.

LAMB, David. Transplantes de órgãos e ética. Tradução de Jorge Curbelo. São Paulo: Sobravime; Ed. Hucitec, 2000.

LIRA, Gerlene Grudka et al. Family considerations about the decision to refuse organ donation. Acta paul. enferm., São Paulo, v. 25, n. esp. 2, 2012. Disponível em <http://www.scielo.br/ scielo.php?script=sci_arttext\&pid=S0103-21002012000900022\&lng=pt\&nrm $=$ iso $>$. Acesso em: 12 nov. 2014. http://dx.doi.org/10.1590/S0103-21002012000900022. 
LOUREIRO, Zuleica Regina de Araújo. Doador de órgãos post mortem: uma vontade sobrestada pelo Art. $4^{\circ}$ da Lei 9434/97. Brasília: FESMPDFT, 2009. Disponível em: <http://www.fesmpdft. org.br/arquivos/mono_zuleica.pdf> Acesso em: 26 mai. 2012.

MARINELE, Marcelo Romão. A declaração de vontade do paciente terminal. As diretivas antecipadas de vontade à luz da Resolução 1995/2012 do Conselho Federal de Medicina. Jus Navegandi, out. 2013. Disponível em: <http://jus.com.br/artigos/25636/a-declaracao-devontade-do-paciente-terminal/2\#ixzz3fgweBMIG>. Acesso em: 29 jul. 2015.

MARINHO,Alexandre.TransplantesdeórgãosnoBrasil.RevistadeDireitoSanitário,SãoPaulo,v.11,n.3, p. 120-122, fev. 2011. Disponível em: <http://www.revistas.usp.br/rdisan/article/view/13224/15039>. Acesso em: 24 nov. 2014. http://dx.doi.org/10.11606/issn.2316-9044.v11i3p120-122.

MORAES, Edvaldo Leal. A recusa familiar no processo de doação de órgãos e tecidos para transplante. 2010. Dissertação (Mestrado) - Escola de Enfermagem, Universidade de São Paulo, 2010. Disponível em: <http://www.teses.usp.br/teses/disponiveis/7/7131/tde-13072007092002/pt-br.php>. Acesso em: 15 abr. 2013.

; MASSAROLLO, Maria Cristina Komatsu Braga. Recusa de doação de órgãos e tecidos para transplante relatados por familiares de potenciais doadores. Rev. Acta Paulista de Enfermagem, São Paulo, v. 22, n. 2. 2009. Disponível em: <http://www.scielo.br/pdf/ape/v22n2/ a03v22n2.pdf>. Acesso em: 30 mai. 2012. http://dx.doi.org/10.1590/S0103-21002009000200003.

NUNES, Maria Inês; ANJOS, Márcio Fabri dos. Diretivas antecipadas de vontade: benefícios, obstáculos e limites. Rev. Bioét., Brasília, v. 22, n. 2, p. 241-251, ago. 2014. Disponível em $<$ http://www.scielo.br/scielo.php?script=sci_arttext\&pid=S1983-80422014000200006\&lng =pt\&nrm=iso $>$. Acesso em: 03 ago. 2015. http://dx.doi.org/10.1590/1983-80422014222005.

OJO, Akinlolu O.; HEINRICHS, Dennis; EMOND, Jean C.; MCGOWAN, Joshua J., GUIDINGER, Mary K.; DELMONICO, Francis L.; METZGER, Robert A. Organ donation and utilization in the USA. American Journal of Transplantation, v. 4, suppl, 9, p. 27-37, 2004. Disponível em: <http://onlinelibrary.wiley.com/doi/10.1111/j.1600-6135.2004.00396.x/pdf >. Acesso em: 17 nov. 2014.

PEREIRA, Caio Mário da Silva. Instituições de direito civil: introdução ao direito civil: teoria geral de direito civil. 24. ed. Rio de Janeiro: Forense. 2011.

PESSOA, João Luis Erbs; SCHIRMER, Janine; ROZA, Bartira de Aguiar. Avaliação das causas de recusa familiar a doação de órgãos e tecidos. Acta paul. enferm., São Paulo, v. 26, n. 4, 2013. Disponível em <http://www.scielo.br/scielo.php?script=sci_ arttext\&pid=S0103-21002013000400005\&lng=pt\&nrm=iso >. Acesso em: 12 nov. 2014. http://dx.doi.org/10.1590/S0103-21002013000400005.

RECH, Tatiana H.; RODRIGUES, Édson Moraes. Entrevista familiar e consentimento. Rev. bras. ter. Intensiva, São Paulo, v. 19, n. 1 mar. 2007. Disponível em <http://www.scielo.br/ scielo.php?script=sci_arttext\&pid=S0103-507X2007000100011\&lng=pt\&nrm=iso $>$. Acesso em: 21 mai. 2012. http://dx.doi.org/10.1590/S0103-507X2007000100011. 
ROSARIO, Elza Nascimento do et al. Recusa familiar diante de um potencial doador de órgãos. Cad. saúde colet., Rio de Janeiro, v. 21, n. 3, set. 2013. Disponível em <http://www.scielo.br/ scielo.php?script $=$ sci_arttext\&pid=S1414-462X2013000300005\&lng $=$ pt\&nrm $=$ iso $>$. Acesso em: 12 nov. 2014. http://dx.doi.org/10.1590/S1414-462X2013000300005.

ROZA, Bartira de Aguiar; ODIERNA, Maria Teresa Aparecida da Silva; GLEZER, Milton; SÁ, João Roberto de. Captação de órgãos para transplantes, 2006. Disponível em: <http://www.abto.org. br/abtov03/Upload/file/Biblioteca_Teses/Textos/CaptacaodeOrgaosLivroEliasKnobellBartira. pdf>. Acesso em: 26 nov. 2014.

SANTOS, Marcelo José dos. A entrevista familiar no processo de doação de órgãos e tecidos para transplante. Dissertação (Mestrado) - Escola de Enfermagem, Universidade de São Paulo, 2010. Disponível em: <http://www.teses.usp.br/teses/disponiveis/7/7136/tde-20052010-105423/ pt-br.php>. Acesso em: 15 abr. 2013.

VENOSA, Sílvio de Salvo. Direito civil: parte geral. 11. ed. São Paulo: Atlas. 2011.

ZÚÑIGA-FAJURIA, Alejandra Increasing organ donation by presumed consent and allocation priority: Chile. Bull World Health Organ., v. 93, p. 199-202, 2015.

Lorena Oliveira Dantas Maynard - Graduada em Direito pela Universidade Católica do Salvador (UCSal). Voluntária em Iniciação Científica, vinculada ao grupo de pesquisa Direitos Humanos, Direito à Saúde e Família (CNPq/UCSal). Salvador/BA, Brasil. E-mail: maynardlorena@gmail.com.

Isabel Maria Sampaio Oliveira Lima -Doutora em Saúde Pública pelo Instituto de Saúde Coletiva, da Universidade Federal da Bahia. Juíza de Direito do Estado da Bahia. Coordena o Grupo Direitos Humanos, Direito à Saúde e Família da Universidade Católica de Salvador. Salvador/BA, Brasil.

Yara Oyram Ramos Lima - Doutora em Saúde Pública; mestre em Saúde Comunitária pela Universidade Federal da Bahia; especialista em Saúde Coletiva na área de Portos, Aeroportos e Fronteiras pela Universidade Federal da Bahia. Pesquisadora no Programa Integrado de Pesquisa, Ensino e Cooperação Técnica em Vigilância Sanitária do Instituto de Saúde Coletiva da Universidade Federal da Bahia. Salvador/BA, Brasil.

Ediná Alves Costa - Doutora em Saúde Pública pela Universidade de São Paulo; mestre em Saúde Comunitária pela Universidade Federal da Bahia; graduada em Medicina Veterinária pela Universidade Federal da Bahia. Professora associada do Instituto de Saúde Coletiva da Universidade Federal da Bahia. Coordena o Programa Integrado de Pesquisa, Ensino e Cooperação Técnica em Vigilância Sanitária e o Centro Colaborador em Vigilância Sanitária no Instituto de Saúde Coletiva da Universidade Federal da Bahia. Salvador/BA, Brasil. 